\title{
Concurrent Validity of Front-Crawl Swimming Competence through Measurement of Basic Swimming Abilities for Beginners
}

\author{
Badruzaman*, Yudha M. Sapoetra, Agus Rusdiana, Jajat, Septian Williyanto \\ Department of Sport Science, Faculty of Sport and Health Education, Universitas Pendidikan Indonesia, Jl. Dr. Setiabudhi No. 229 \\ Bandung, Indonesia
}

Received April 23, 2021; Revised June 15, 2021; Accepted July 19, 2021

\section{Cite This Paper in the following Citation Styles}

(a): [1] Badruzaman, Yudha M. Sapoetra, Agus Rusdiana, Jajat, Tono Haryono , "Concurrent Validity of Front-Crawl Swimming Competence through Measurement of Basic Swimming Abilities for Beginners," International Journal of Human Movement and Sports Sciences, Vol. 9, No. 4A, pp. 8 - 14, 2021. DOI: 10.13189/saj.2021.091302.

(b): Badruzaman, Yudha M. Sapoetra, Agus Rusdiana, Jajat, Tono Haryono (2021). Concurrent Validity of FrontCrawl Swimming Competence through Measurement of Basic Swimming Abilities for Beginners. International Journal of Human Movement and Sports Sciences, 9(4A), 8 - 14. DOI: 10.13189/saj.2021.091302.

Copyright $\odot 2021$ by authors, all rights reserved. Authors agree that this article remains permanently open access under the terms of the Creative Commons Attribution License 4.0 International License

\begin{abstract}
The study aimed to examine the concurrent validity of front-crawl swimming competence as a criterion by measuring the basic swimming ability for estimated swimming distance. The research samples were 35 students (15 people from the Sports Science program and 20 from the Physics program) aged 19-21. The seven components of basic swimming ability, including submerging, floating, gliding (Gd), leg propulsion, hand propulsion, leg coordination, and breath control, were the predictors, while the front-crawl swimming competence referred to the criterion. Concurrent validity analysis used PPM correlation, while factor analysis used stepwise multiple regression methods. The results indicated a significant association between basic swimming abilities and swimming competence. The moderate relationship ( $\mathrm{r}=04-0.7, \mathrm{p}<0.01$ ), was found in gliding, leg propulsion, hand propulsion, hand and leg coordination, and breath control. While the relationship in the ability to submerge and float is weak $(r=0.22$ and $0.16, p<0.05)$. Basic swimming ability as an estimator of swimming competence has a significant concurrent validity in the moderate level, except for the basic ability to dive and float, which were in the weak category. Only two factors are estimated to have the greatest influence on the beginner's front-crawl competence achievement, namely basic ability to control breathing and coordination of legs $\&$ hands.
\end{abstract}

Keywords Concurrent Validity, Swimming Competence, Basic Swimming Ability, Measurement

\section{Introduction}

Having swimming competence is important, especially as a preparation for possible drowning accidents [1]. There are many benefits associated with the ability to swim. Increased swimming competence is almost certain to be protective in drowning situations. Differences in swimming competence may explain why some are at a greater drowning risk than others [2]. Swimming competence has environmental characteristics that are different from activities on land. In addition to requiring a general motor ability, it must also have special abilities required in the water environment. The success of one's swimming competence can be determined by these special basic abilities, such as ability to dive, float, glide, leg motion to push (leg propulsion), arm movement to push (hand propulsion), coordination of leg \& arm movements, and the ability to take a breath (breath control) [3]. This basic swimming ability is a battery that can be used as a measure to estimate the achievement of swimming competence [4]. Floating, diving, underwater swimming, and swimming for technique are basic water competency 
skills. Yet, these skills are essential aspects of the concept of water competence [5]. Meanwhile, between 15-20\% are unable to swim at a distance of 25 meters. Reviewing the reality of the problem's condition encourages the assessment of basic swimming skills to estimate swimming competence as a criterion through concurrent validity testing.

Measuring basic swimming skills for the beginning includes fear removing test, submerging test, floating test, gliding test, and full stroke forward movement. Findings show submerge 1.4 (W2), 4.3 (W4), 7.5 (W6), floating 3.5, 4.3, 7.5, gliding 4.6 (W4) 7.4 (W6) (6), and full stroke 6.67 [7]. Eight skill elements emerged finally as both irreducible and irreplaceable within a beginner swimming course [8]. A study on children swimming $25 \mathrm{~m}$ and declared as 'swimmers' shows that one quarter $(26 \%)$ of them could not enter deep water by either a jump or dive. In other university students, most of them (76\%) could comfortably swim more than $300 \mathrm{~m}$ nonstop, but only $40 \%$ who could float for 15 minutes. Such grouping facilitates diagnosis, forces a more balanced and comprehensive outline of instruction, and affords a helpful pattern for selecting practical skills [9]. Actual performance evaluation was also used to identify the respondents' swimming ability level through a rubric [10]. The obtained data show that our athletes achieved a similar distance when gliding supine or prone distance, float, and back float. This test battery included specific skills from levels 1-5 of the American Red Cross Learn to Swim Program [1].

A powerful positive and significant relationship was observed between self-reported ability to swim and selfreported number of laps [11]. There is a weak correlation between practical skills tests and survey methods [12]. The arm propulsive motion phase was observed to generate strong vortical structures that travel along the body and toward the kicking legs. Most of the arm propulsion was generated when the hands were moving backward. The breathing actions of the non-expert swimmers amplified their asymmetric coordination on the breathing side [13]. The swimmer was modeled as if he was gliding underwater in a streamlined prone position, with hands overlapping and head between the extent [14].

Theoretically, the ability is a trait presence that underlies or contributes to success in several related skills [15]. The term abilities can also be interpreted to refer to a person's potential movement competencies instead of actual movement performances [16]. Movement behaviors are not based on a singular global ability, but also on many specific abilities, perhaps thousands [17]. The particular abilities underlying springboard diving are entirely different from those underlying tenis performance.

The ability has implications for one's performance in various activities, including swimming. An individual is said to have a high level of ability to carry out complex tasks [17]. It should be considered that swimming is separated from the other sports mainly because of the body's prone position, the controlled respiration caused by water immersion, and the fluctuant environment in which forces are applied [18]. The ability to submerge with open eyes substantially advanced the learning process [19].

Term of water competency is a more comprehensive term than swimming ability and better describes a raft of aquatic skills and knowledge associated with aquatic activity [20]. Swimming researchers also contribute to initiating new techniques, drills, teaching, and training methods based on scientific principles [22]. A beginner was any subject who could not swim one length $(25 \mathrm{yd}$.) $(22.86 \mathrm{~m})$ [21]. Therefore, this study aimed to test the concurrent validity to confirm the relationship between basic swimming ability as predictor factors and frontcrawl swimming competence as a criterion, not as a measurement test to prepare for the prevention of drowning accidents.

\section{Methods}

The research subjects consisted of 35 students (age 1920). 20 students were from the Sports Science study program and 15 students were from the Physics study program (28 males and 12 females). Subjects were beginner swimmers who have not been able to swim at a distance of $25 \mathrm{~m}$ [21]. A beginner was any subject who could not swim one length $(25 \mathrm{yd}$.). The subject had not been given a swimming learning program in this study. The distance covered was considered the criterion. This study was limited only to the concentration on front crawl stroke to sharpen the focus of the further analysis. Interestingly, in Canada and Australia, learn-to-swim programs primarily emphasize teaching and learning the front crawl stroke. The front crawl is easy and considered as the fastest and most efficient style [24].

\section{Instrument}

To test the concurrent validity, a direct practice test and measurement of basic motor skills with a swimming competition test that refers to the concept as described were conducted. Likewise, the content of basic swimming ability referred to the validity of the construct. The basic swimming ability content being considered included diving ability test (seconds), buoyancy test (seconds), glide ability test (distance), leg motion test to push, arm motion test to push, leg and arm coordination test, and breath control, as predictors. Swimming performance is determined by generating propulsive force while reducing the resistance to forwarding motion [25].

\section{Procedure}

The first test item was head and whole-body immersion, 
then the body float test, glide test, leg motion test, arm motion test, leg \& arm coordination test, and breathtaking test. The last was the swimming distance competence test. The test for each item was carried out in groups of 5 people. In the diving test, students held iron and began preparations to stand facing the edge of the pool. After the signal of the whistle, all students had to put their heads in the water simultaneously. Along with the whistle sound, the stopwatch was pressed. Measurements were recorded in seconds once each subject's head comes out of the water.

Float test execution procedure included 1) the first subject was ready to stand in line with wings facing the pool wall, one meter from the wall, 2) when hearing the whistle sound, immediately the whole testee/subject floated his body to the surface of the water and maintained it as long as possible, 3) simultaneously with the sound of the whistle, the stopwatch was switched on, 4) the measurement was recorded in seconds when the teste's head had come out of the water surface or the feet had touched the floor. Glide test procedure included preparation of the testee standing against the pool wall, one leg bent, and the sole of his foot also attached to the pool wall. At the signal of the whistle, the testee slid by turning his feet against the pool wall, then slid his body as far as possible.

\section{Analysis}

Concurrent validity analysis used Pearson productmoment partial correlation. Factor analysis used multiple linear regression with the Stepwise method. The correlation value $<0.4$ represented poor correlation, 0.4 to 0.7 fair, 07 to 0.9 good, and $>0.9$ excellent [25]. All statistical calculations used the Statistical Package for Social Science (SPSS v.25) and the level of significance was $<0.05$.

\section{Results}

Table 1 shows basic swimming ability and swimming competence, including submerging, floating, gliding, leg propulsion, hand propulsion, coordination of leg \& hand propulsion, breath control, and swimming competence. The measurement of mean, minimum score, maximum score, range, standard deviation, and standard error of all variables are shown in Table 1.

According to Table 2, there were two components of basic swimming ability that have no significant concurrent validity with swimming competence, namely the ability to dive and float with a correlation coefficient value below $r=0.30$. Meanwhile, there were five components of basic swimming ability which have a significant correlation coefficient in a moderate category, namely gliding with SC $(p<0.01)$, leg propulsion with swimming competence ( $p<0.01)$, HP with SC value $r=0.604$, CL \& HP propulsion with SC ( $\mathrm{p}<0.01)$, and BC with SC ( $\mathrm{p}<0.01)$. The highest concurrent validity score was obtained between breathing ability and swimming competence with $r=0675$ in the moderate relationship category.

Only two variables were selected into the regression model that met the Probability of $\mathrm{F}$ to enter criteria $<=0.05$ or $>=0.10$, namely the breath factor (see Table 3), breath control, and coordination of leg \& arm movements. Model 1, R2 value for breath factor, was 0.456 (45.6\%). Basic ability to breath in swimming (BC) had a contribution of $45.6 \%$ to front crawl swimming competence. The basic ability to breath simultaneously with the legs and arms coordination contributes $58.7 \%$ to front crawl swimming competence. Other factors contributed to the remaining $40.3 \%$.

In Table 4, the ability to breath had a significant impact on swimming distance competence $(\mathrm{p}<0.00)$. This means that model 1 breath control can be used to predict swimming competence. Model c, the ability to breath and the coordination movement of the legs \& arms as a predictor, had a value of $\mathrm{F}=22.75, \mathrm{p}<0.00$. The two essential swimming ability factors, including ability to take breath and leg and arm coordination, significantly affected the student front crawl swimming competence.

Table 5 shows that the breath factor had a significant effect on swimming competence. Likewise, the leg \& arm coordination factor had a significant impact on swimming competence $(\mathrm{p}<0.05)$. Thus, it was selected into the stepwise regression model.

Table 1. Descriptive data of basic swimming ability and swimming competence

\begin{tabular}{|c|c|c|c|c|c|c|c|c|}
\hline No & Dependent and Independent Variable & Measure & Mean & Minimal & Maximal & Range & Sd. & SEE \\
\hline 1 & Submerge (Sm) & second & 17 & 1.60 & 27.59 & 25.99 & 5.26 & 0.88 \\
\hline 2 & Floating (Ft) & second & 16 & 1.00 & 52.95 & 51.94 & 9.60 & 1.62 \\
\hline 3 & Glide (Gd) & meter & 3.51 & 0.00 & 7.00 & 7.00 & 1.40 & 0.23 \\
\hline 4 & Leg Propulsion (LP) & meter & 5.51 & 3.00 & 9.00 & 6.00 & 1.77 & 0.29 \\
\hline 5 & Hand Propulsion (HP) & meter & 7.90 & 5.00 & 11.00 & 6.00 & 1.62 & 0.27 \\
\hline 6 & Coordination of Leg \& Hand Propulsion (CL & meter & 9.14 & 4.00 & 14.00 & 10.00 & 2.26 & 0.38 \\
\hline 7 & \& HP) & frequency & 1.80 & 0.00 & 4.00 & 4.00 & 1.05 & 0.17 \\
\hline 8 & Breath Control (BC) & meter & 10.94 & 7.00 & 15.00 & 8.00 & 2.01 & 0.34 \\
\hline
\end{tabular}


Table 2. Concurrent validity correlation matrix between swimming basic ability and swimming competence

\begin{tabular}{|c|c|c|c|c|c|c|c|c|}
\hline S.B.A. & S.C. & Submerge & Floating & Glide & LP & HP & CL \& HP & BC \\
\hline Submerge & 0.223 & 1 & -0.052 & 0.072 & 0.112 & 0.115 & 0.089 & 0.217 \\
\hline Floating & 0.161 & & 1 & $0.474 * *$ & -0.147 & -0.088 & 0.027 & 0.126 \\
\hline Glide & $0.438^{* *}$ & & & 1 & $0.423^{*}$ & 0.223 & $-0 . .024$ & $0.411^{*}$ \\
\hline L.P & $0.602^{* *}$ & & & & 1 & $0.758^{* *}$ & 0.201 & $0.641^{* *}$ \\
\hline H.P & $0.604^{* *}$ & & & & & 1 & $0.570^{* *}$ & $0.490^{* *}$ \\
\hline CL \& HP & $0.466^{* *}$ & & & & & & 1 & 0.161 \\
\hline BC & $0.675^{* *}$ & & & & & & & 1 \\
\hline
\end{tabular}

Table 3. Results analysis of stepwise multiple regression linear methods

\begin{tabular}{|c|c|c|c|c|c|c|}
\hline Model & Predictors Variable & R & R Square & $\begin{array}{c}\text { Adjusted } \\
\text { R Square }\end{array}$ & Std. Error of Estimate & Durbin-Waston \\
\hline 1 & Breath Control & $0.675 \mathrm{a}$ & 0.456 & 0.439 & 1.50824 & \\
\hline 2 & Breath Control, CL \& HP & $0.766 \mathrm{~b}$ & 0.587 & 0.561 & 1.33390 & 1.529 \\
\hline
\end{tabular}

Table 4. Results of ANOVA test

\begin{tabular}{|c|c|c|c|c|c|c|}
\hline Model & & Sum of Squares & df & Mean Square & F & Sig. \\
\hline \multirow{3}{*}{1} & Regression & 62.818 & 1 & 62.818 & 27.615 & $0.000 \mathrm{~b}$ \\
\cline { 2 - 7 } & Residual & 75.068 & 33 & 2.275 & & \\
\cline { 2 - 8 } & Total & 137.886 & 34 & & & \\
\hline \multirow{3}{*}{2} & Regression & 80.948 & 2 & 40.474 & 22.747 & $0.000 \mathrm{c}$ \\
\cline { 2 - 8 } & Residual & 56.938 & 32 & 1.779 & & \\
\cline { 2 - 8 } & Total & 137.886 & 34 & & & \\
\hline
\end{tabular}

Table 5. T-test and multicollinearity test

\begin{tabular}{|c|c|c|c|c|c|c|c|c|}
\hline Model & & B & Std. Error & Beta & t & Sig. & Tolerance & VIF \\
\hline 1 & (Constant) & 8.616 & 0.511 & & 16.865 & 0.000 & & \\
\hline & Breath C & 1.293 & 0.246 & 0.675 & 5.255 & 0.000 & 1.000 & 1.000 \\
\hline \multirow{2}{*}{2} & (Constant) & 5.832 & 0.928 & & 5.937 & 0.000 & & \multirow{2}{*}{0.974} \\
\hline & Breath C & 1.180 & 0.220 & 0.616 & 5.352 & 0.000 & 1.026 \\
\hline & CL \& HP & 0.327 & 0.102 & 0.367 & 3.192 & 0.003 & 0.974 & 1.026 \\
\hline
\end{tabular}

\section{Discussions}

Based on the results, there was a relationship between basic swimming ability factors and front crawl swimming distance competence. Five basic swimming ability factors significantly correlated in the moderate category with front crawl swimming competence. The five factors were gliding capability, leg propulsion, hand propulsion, leg and arm coordination, and breath control. Two factors had a weak correlation. They were the ability to dive and float. It could be understood because these two basic swimming abilities do not generate distances. However, the ability to dive in swimming has a vital role. It is the first foundation that must be implanted to facilitate float and move forward [19].

The ability to immerse the body and float in the water are the basic abilities to support the next ability. People who have difficulty engaging their bodies in the water will have problems floating their bodies to the water's surface. Likewise, the essential ability to float serves to make it easier for the body to move above the water surface. Thus, the ability to float has a vital role in the sufficient swimming competence to cover a certain distance compared to those without buoyancy [26]. A body's ability to float is important in most aquatic sports. The basics are that your body is lighter than water and floats [27]. Staying afloat is a major contributor to survival in an aquatic emergency. It is suggested that learning and mastering floating skills under unsteady, wavy water conditions may comprise an essential aquatic skill competence for the novice swimmer [5]. The results of previous studies explain that the ability to dive, float, and glide has a contribution to swimming distance abilities [28].

The ability to swim more dominantly results from the encouragement of leg and arm movements and the ability 
to breath. Most of the arm propulsion is generated when the hands are moving backward [12]. The ability to move arms has a similar contribution to leg movement, which is $33.4 \%$ for swimming distance competence. This happens, based on observations, because their arm movements still do not have the correct technique, so they have not yet produced a maximum propulsion power. In contrast to trained swimmers/athletes, front-crawl stroke arm movement contributes $70-80 \%$ greater than leg movements' contribution [29]. It is not surprising that the hand and forearm are seen as the major propelling surfaces responsible for $>85 \%$ of the total propulsion in able-bodied front-crawl swimming [30]. The motion makes the propulsive force of the hand in front-crawl and backstroke, except for the breaststroke.

The ability to swim can take a breath [13] in non-expert swimmers, leading to suggestions that breathing may affect arm coordination. Swimmers roll further when taking a breath. A person who cannot take a breath will produce a limited swimming distance because of running out of oxygen. Conversely, if he can take a breath, he will continuously increase his physical strength to increase his swimming distance.

The stepwise multilinear regression test results were more convincing that two entered models were selected from seven basic swimming abilities, namely the ability to breath (breath control) and the coordination of leg and arm movements. It means that in front-crawl swimming competence for beginner swimmers, the strength of the carrying capacity lies in the collaboration between taking a breath and the coordination of leg \& arm movements. It is consistent with the concept highlighting two essential aspects of swimming, named floating to permit breathing and propulsion to provide mobility. Understanding the interactions of arm coordination, leg kicks, and the body roll during arm strokes and breathing is essential [13]. In the whole stroke, coordination of arm and leg superposition coordination appears as the main solution over a critical speed of 1.8 m.s [31].

The concurrent validity test results between basic swimming ability and front-crawl swimming distance competence for beginners are in the moderate category on average. This fact is acceptable because all of the basic movement abilities performed have not been shown in the quality of movement techniques. Following the other findings, the swimming technique was given a low score [19]. Unskilled swimmers frequently have inadequate body roll [32]. Any two tests that had correlations of 0.70 or less were said to be specific [3]. Previous findings show that interval training has been related to freestyle swimming skills adolescent athletes [33]. In other words, measuring skills in sports is essential and must have good validity and reliability [34].

\section{Conclusions}

It concludes that the seven basic swimming abilities presented as content and predictors of swimming competence as a criterion had positive and significant concurrent validity in the weak to moderate category. Two basic swimming abilities had concurrent validity in weak categories, namely the ability to dive and float. The five basic swimming skills had moderate concurrent validity. In the seven basic skills stepwise method, only two were selected to be the variable involved into two models. The concurrent validity between basic swimming ability as an estimator and the front-crawl swimming distance competence as a criterion for beginners had concurrent validity in the weak to moderate category.

\section{Acknowledgement}

The authors would like to thank all the students who participated in the study and the Universitas Pendidikan Indonesia for allowing us to use swimming pool facilities during data collection.

\section{REFERENCES}

[1] Berukoff Karen D. And Hill Grant M., "A Study of Factors That Influence the Swimming Performance of Hispanic High School Students," International Journal of Aquatic Research and Education, 2010, 4, 409-421. Human Kinetics.

[2] Brenner Ruth A., Saluja Gitanjali, and Smith Gordon S., "Swimming Lessons, Swimming Ability, and the Risk of Drowning. Injury Control and Safety Promotion," Vol. 10, No. 4, pp. 211-215, 2003. (Swets \& Zeitlinger.

[3] Morrow James R., Jackson Allen W., Disch James G., Mood Dale P., "Measurement and Evaluation in Human Performance". Human Kinetics. USA: 2011.

[4] Stallman Robert K., Kevin Moran, Linda Quan, Langendorfer Stephen, "From Swimming Skill to Water Competence: Towards a More Inclusive Drowing Prevention Future," International Journal of Aquatic Research and Education: Vol. 10: No. 2 Article 3. DOI: 10.25035/ijare.10.02.03. 2017.

[5] Kjendlie Per-Ludvik and Mendritzki Marcel, "Movement Patterns in Free Water Play After Swimming Lessons With Flotation Aids," International Journal of Aquatic Research and Education, 2012, 6, 149-155. Human Kinetics.

[6] Thoke Atmaram Vaman, "Development of Basic Skills in Swimming Sports Training at Grass Root Level Through Distance Education Method: A Case Study on School Going Children," Journal of Sports and Physical Education IOSR-JSPE. e-ISSN: 2347-6745, p-ISSN: 2347-6737, 2006. Volume 1, Issue 1. www.iosrjournals.org. 
[7] Erfan Al Shimaa Saad Zaghlol, "The Effect of Float Tools on Some Basic Skills Performance in Swimming and Some Physiological Variables for Students in Faculty of Psycal Education," Cience, Movement and Healt, Vol. XIV, ISSUE 1, 2014, 14 1.: 14-18.

[8] Stallman Robert K., Junge Malfrid, and Blixt Turid, "The Teaching of Swimming Based on a Model Derived from the Causes of Drowning," International Journal of Aquatic Research and Education. Vol. 2/ Number 4. Article 11-12008. DOI: 10.25035/ijare.02.04.11.

[9] Cureton Thomas K., "Standards for Testing Beginning Swimming," Research Quarterly. American Association for Health, Physical Education and Recreation, 10:4, 54-59. Springfield College, Massachusetts, USA. http://dx.doi.org/10.1080/10671188.1939.10622511. 2015.

[10] Capitulo P. and Martin Jonar., "Assessment of a Proposed Freestyle Swimming Skills Improvement Program for Female College Students," International Journal of Physical Education, Fitness and Sports. Journal homepage: www. Ij p e f s. Non-Olympic times. Org. ISSN: 2277: 5447 / Vol. 4. No. 1/ March' 2015.

[11] Petrass Lauren A., Blitvich Jennifer D., Harvey Jack, Moran Kevin, "Can You Swim? Self-Report and Actual Swimming Competence among Young Adults in Ballarat," Australia. International Journal of Aquatic Research and Education, 2012, 6, 136-148. Human Kinetics.

[12] Cohen R.C., Cleary Paul W., Mason Bruce R., and Pease David L., "The Role of the Hand during Freestyle Swimming. Journal of Biomechanical Engineering," September 2015. DOI: 10.1115/14331585.

[13] Seifert L., Chollet D., Allard P., "Arm Coordination Symmetry and Breathing Effect in Front Crawl," Human Movement Science 24 2005. 234-256. Elsevier B.V. doi:10.1016/j.humov.2005.05.003.

[14] Novais Maria L., Silva Antonio J., Mantha Vishveshwar R., Ramos Rui J., "The Effect of Depth on Drag During the Streamlined Glide: A Three-Dimensional CFD Analysis," Journal Human Kinetics Volume 33/2012, 55-62 DOI: 10.2478-012-0044-2. Section I - Kinesiology.

[15] Singer, Robert, N., "Motor Learning and Human Performance, an Application to Moloi Skill and Movement Behaviors". New York: Macmillan. 1980.

[16] Burton Allen W. And Miller Daryl E., "Movement Skill Assessment," Human Kinetcs, USA, 1998, ISBN:0-87322975-4.

[17] Schmidt, Richard A. and Wrisberg Craig A., "Motor Learning and Performance," USA: Human Kinetics, 2000.

[18] Dalamitros A., Manaou Vasiliki., Pelarigo Jalitong G., "Laboratory-based test for swimmers: Methodology, reliability, Considerations and Relationship with FrontCrowl Performance," Journal of Human Sport \& Exercise. 2014/ISSUE 1/ Volume 9. Doi:10.4100/jhse.2014.91.17.

[19] Statkeiciene B. and Venckunas T., “Athletes' Anthropometrical Measurements and Physical Capacity Influence on Learning Competitive Swimming Techniques," ACTA MEDICA LITUANICA, 2008. Vol. 15 No. 4.P 229-234.
[20] Moran Kevin, Stellman RK., Kjendlie Per-Ludvik, Dahl Dagmar, Blitvich Jenifer D., Petras Laurent A., "Can You Swim An Exploration of Measuring Real and Perceived Water Competency", International Journal Aquatic Research and Education, 2012, 6, 122-135.

[21] Holt Alyce, Thorpe Joanne, \& Thorpe Joanne, "Two Methods of Teaching Beginning Swimming," Research Quarterly. American Association for Health, Physical Education and Recreation, 41: 3, 371 - 377. http://dx.doi.org/10.1080/10671188.1970.10614984.2015. Publisher: Routledge. London.

[22] Pelayo Patrick, Michel Sidney, Kherif Tarik, Chollet Didier, and Tourny, "Stroking Characteristics in Freestyle Swimming and Relationships With Anthropometric Characteristics," Journal of BIOMECHANICS, 1996, 12, 197-206 @1996, Human Kinetics Publisher, Inc.

[23] Langendorfer S., "Which Stroke First?," International Journal of Aquatic Research and Education, 2013, 7, 286289. Human Kinetics, Inc.

[24] Sheard Michael and Golby Jim, "Effect of a Psychological Skills Training Program on Swimming Performance and Positive Psychological Development," USEP, 2006, 4 149169. PST Program in Swimming. West Virginia University.

[25] Tompestt Claire, et al., "Comparing Performances of Fundamental Movement Skills and Basic Human Movements," A Pilot Study. Journal of Fitness Research. ISSN 2201 - 5655 (c) 2015, Australian Institute of Fitness.

[26] Hay James G., The Biomechanics of Sports Techniques. Prentice-Hall: USA, 1993.

[27] Thomas D., "SWIMMING Steps to Success", Leisure Press: New York, 1989.

[28] Badruzaman, Rusdiana, Syahid, "The Contribution of Submerge, Floating, and Gliding Ability on Swimming Distance Ability for First-Year College Student," 4th International Conference on Sport Science, Health, and Psycal Education ICSSHPE 2019. Proceeding. Vol: /issue: 12020. Advance in Health Science Research, Vol. 21. Atlantis Press.

[29] Osborough Cornor, Daly Daniel and Payton Carl., "Effect of swim speed on leg-to-arm coordination in unilateral arm amputee front crawl swimmers," Journal of sports, Science, 2015. Vol. 33, No. 14, 1523-1531, http://dx.doi.org/10.108 0/02640414.2014.996181.

[30] Siljeg Klara, Sindik Josko, and Leko Goran, "Swim Speed Tests as a Method for Differentiating the Profiles of Young Swimmers," Monten. J. Sports Sci. Med. 6 2017. 2: 19-26. UDC 797.2.

[31] Seifert Ludovic et al., "Arm Coordination, Power, and Swimming Efficiency in National and Regional Front Crawl Swimmers," Human Movement Science. Elsevier, 2010, 29 3., pp.126. 10.1016/J.humov. 2009.11.003 hal00640441.2010 .

[32] Reiwald Scott and Rodeo Scott., "Science of SWIMMING FASTER,” Human Kinetics: USA.,2015.

[33] Edi Wahyudi M , Yudi Hendrayana , Amung Ma'mun , Boyke Mulyana, "Aerobic Interval Training in Freestyle Swimming," International Journal of Human Movement 
14 Concurrent Validity of Front-Crawl Swimming Competence through Measurement of Basic Swimming Abilities for Beginners

and Sports Sciences, Vol. 8, No. 4, pp. 142 - 146, 2020. DOI: $10.13189 /$ saj.2020.080406.

[34] Dewangga Yudhistira, Tomoliyus, "Content Validity of
Agility Test in Karate Kumite Category," International Journal of Human Movement and Sports Sciences, Vol. 8, No. 5, pp. $211 \quad$ - 216, 2020. DOI: 10.13189/saj.2020.080508. 